\title{
An institutional study of cesarean delivery on maternal request
}

\author{
A. Shanti Sri*, Nazia Khanam \\ Department of Obstetrics and Gynecology, Princess Esra Hospital Deccan College of Medical Sciences Hyderabad, \\ Telengana, India \\ Received: 02 June 2017 \\ Accepted: 07 June 2017

\section{*Correspondence:} \\ Dr. A. Shanti Sri, \\ E-mail: shantisrinivas@gmail.com \\ Copyright: (c) the author(s), publisher and licensee Medip Academy. This is an open-access article distributed under \\ the terms of the Creative Commons Attribution Non-Commercial License, which permits unrestricted non-commercial \\ use, distribution, and reproduction in any medium, provided the original work is properly cited.
}

\begin{abstract}
Background: Cesarean delivery on maternal request refers to a primary cesarean delivery performed because the mother requests this method of delivery in the absence of a standard medical/obstetrical indication for avoiding vaginal birth. The aim of the study was to find out the reasons behind, and the incidence of women preferring Cesarean section in the absence of obstetric and medical indications.

Methods: This was a prospective study among women who came for delivery at Princess Esra Hospital, Deccan College of Medical Sciences, Hyderabad, over a period of one year from $1^{\text {st }}$ April 2015 to $31^{\text {st }}$ March 2016. All women who underwent Cesarean delivery for maternal request were included in this study.

Results: The total number of deliveries during the study period of one year was 2574 . There were $1346(52.29 \%)$ vaginal deliveries and 1228 (47.7\%) cesarean deliveries. Among 1228 Cesarean deliveries, 87 (7.08\%) had maternal request as their indication. Majority of them were in the age group of more than 35 years. Multigravidae opted for Cesarean delivery more than primigravidae (59 multigravidae vs 28 primigravidae). Among the various reasons for women requesting delivery cesarean were tocophobia, refusal of trial of labor after Cesarean section (TOLAC), concurrent sterilization, prolonged infertility and treatment conception, afraid of neonatal outcome (previous adverse neonatal outcome) and astrological concerns.

Conclusions: Many of the women opted for Cesarean delivery in our study for preventable reasons like painless labor and concurrent sterilization which would have been easily avoided by prior counseling starting from antenatal period and by providing labor analgesia. Patient education and personal involvement of the treating obstetrician in counseling the patient and emotional support during labor can reduce Cesarean delivery for maternal request.
\end{abstract}

Keywords: Cesarean section, Maternal request, Tocophobia, Vaginal deliveries

\section{INTRODUCTION}

Cesarean delivery on maternal request refers to a primary cesarean delivery performed because the mother requests this method of delivery in the absence of a standard medical /obstetrical indication for avoiding vaginal birth. ${ }^{1,2}$ It is estimated that $4-18 \%$ of all cesarean sections are done on maternal request; however, estimates are difficult to come by. ${ }^{3}$ While uncommon in the past, a recent national audit in the United Kingdom revealed that
$7 \%$ of all elective cesarean sections were performed for precisely this reason. ${ }^{4}$ Not surprisingly, $69 \%$ of the obstetricians, when come across a woman requesting for cesarean delivery, would comply with such a wish. ${ }^{5}$ The high rate of cesarean sections could be attributed to four main reasons; first is the lack of a dedicated obstetric anesthetic staff member to offer epidural analgesia within the labor wards; second, the more liberal view of cesarean section as an accepted mode of delivery by junior obstetricians, especially at the emergency unit; 
third, the observed low rate of successful vaginal birth after cesarean (VBAC) (22.23\%); and fourth, the absence of any evidence of attempted instrumental (forceps and ventouse) deliveries in many instances where it may have been successful. ${ }^{6}$

WHO has stated that no empirical evidence exists for an ideal caesarean rate, but what matters most is that all women who need caesarean sections actually receive them. ${ }^{7}$ In areas with very high mortality rates, such as Africa, inadequate availability of caesarean section contributes to substantial maternal and perinatal morbidity and mortality. ${ }^{8}$ Conversely, in many developed countries, concerns exist about high rates of caesarean section, since increasing rates of this procedure show little evidence of leading to further improvement in perinatal outcome. ${ }^{9}$ One among the reasons for the rising cesarean delivery rate is maternal request for Cesarean delivery.The possibilities for opting for caesarean section are multifactorial. Commonly quoted reasons are tocophobia, previous poor experiences with labor, or concern about specific outcomes including prolapse, anal and urinary incontinence, fetal injury, uncertainty of outcome of a trial, and need for emergency cesarean or assisted vaginal delivery.

An increasing number of surveys have investigated women's reason for Cesarean section, the ethics of doing such Cesarean section and whether proper counseling prior to the surgery will reduce the Cesarean section rate. A study published in 2006 comprising 86 pregnant women with fear of birth and a request for planned cesarean was referred for counseling and found that $86 \%$ changed their original request for Cesarean section and preferred to deliver vaginally. ${ }^{10}$ Thus, the aim of this study was to find out the reasons behind women preferring Cesarean section in the absence of obstetric and medical indications.

\section{METHODS}

Total study period was for one year from $1^{\text {st }}$ April 2015 to $31^{\text {st }}$ March 2016 Totally 87 women were included in this study. Among 87 women, 28 were primigravida and 59 were multigravida. The age of each woman, parity and previous mode of delivery in case of multigravidity were recorded. Women who opted for cesarean delivery on maternal request were put through a written questionnaire about the reason for opting cesarean.

\section{Inclusion criteria}

- All women who underwent CS for maternal request, both primigravida and multigravida were included.

\section{Exclusion criteria}

- Cesarean section performed for any obstetric or medical indications like cephalo pelvic disproportion, malpresentations, placenta previa, fetal distress, etc.

\section{RESULTS}

In this prospective study, a total of 87 women were included. Majority $(29.88 \%)$ of them were in the age group of 31-35 years. Multigravida opted for Cesarean section more than primigravida (59 versus 28). All the patients in this study underwent Cesarean section at term gestation. Table 1 shows demographic data of all the patients included in the study and Table 2 shows details of gravidity of the patients in this study.

\section{Table 1: Age group.}

\begin{tabular}{lll} 
Age & Number & Percentage \\
\hline$<20$ years & 5 & 5.74 \\
\hline 20-25 years & 16 & 18.39 \\
\hline 26-30 years & 12 & 13.79 \\
\hline 31-35 years & 26 & 29.88 \\
\hline$>35$ years & 28 & 32.18 \\
\hline
\end{tabular}

Table 2: Primigravidae vs multigravidae.

\begin{tabular}{|lll|} 
Gravidity & Primigravida & Multigravida \\
\hline Numbers & 28 & 29 \\
\hline Percentage & $32.18 \%$ & $67.81 \%$ \\
\hline
\end{tabular}

28 primigravidae underwent caesarean delivery on maternal request, six for tocophobia despite counseling regarding available pain relief methods and birth companion, four for astrological reasons, five of them when explained regarding trial of labor opted for caesarean delivery due to uncertainty of the outcome. Thirtee primis had prolonged infertility and conceived after treatment wanted a safe delivery by caesarean section.

Among the multigravidae who underwent Cesarean section for maternal request in the study group, 36 had previous CS and the rest 23 had prior vaginal delivery. Among the 36 multigravida with previous delivery by caesarean section for a non-recurrent indication, the patients were given the option of trial of labor after caesarean section (TOLAC). Three of them opted for caesarean section as they were not ready to go through labor for fear of pain. Five women refused TOLAC for the fear of complications. Twelve of them refused the trial of labor as they wanted concomitant sterilization. One woman who had an abdominal delivery lost her child at infancy and did not want to take any risk. Seven of them had a previous Cesarean section earlier had prolonged infertility and wanted an elective repeat Cesarean section. Three women insisted for Cesarean as they wanted baby extraction at a particular time due to astrological concerns.

23 multigravidae who had previous normal deliveries, underwent Cesarean delivery on maternal request. Six 
women with prior vaginal delivery were not ready to tolerate the pain again, six of them insisted for concomitant sterilization, 11 of them had previous poor neonatal outcomes, and five of them wanted an abdominal delivery as their pregnancy resulted after prolonged infertility.

Table 3: Reason for caesarean delivery on maternal request.

\begin{tabular}{|lll|}
\hline Indication & $\begin{array}{l}\text { No. of } \\
\text { Primi- } \\
\text { gravidae }\end{array}$ & $\begin{array}{l}\text { No. of } \\
\text { Multi- } \\
\text { gravidae }\end{array}$ \\
\hline Tocophobia & 6 & 9 \\
\hline Astrological reasons & 4 & 3 \\
\hline $\begin{array}{l}\text { Concomitant sterilization } \\
\text { Previous poor neonatal } \\
\text { outcome }\end{array}$ & - & 18 \\
\hline Not willing for TOLAC & - & 12 \\
\hline $\begin{array}{l}\text { Uncertainty of outcome of } \\
\text { trial of labor }\end{array}$ & 5 & 5 \\
\hline $\begin{array}{l}\text { Prolonged infertility and } \\
\text { treatment conception }\end{array}$ & 13 & 12 \\
\hline
\end{tabular}

\section{DISCUSSION}

Women should be provided with information available about childbirth issues and appropriate support may make them more comfortable for attempting vaginal birth. The reason for opting for cesarean delivery should be determined and addressed. Tocophobia may be tackled by providing information about obstetric analgesia and anesthesia, as well as consultation with an anesthesiologist. Anxiety and fear arising from personal trauma, previous childbirth experiences, should be addressed. The doctor-patient relationship is complex and private, requiring mutual respect and trust. The patient's right to refuse or limit treatment is well tested and universally acknowledged, but the opposite right to request certain interventions, while perfectly acceptable in many situations seems to have caused significant controversy with respect to Cesarean section. ${ }^{11}$

The total number of deliveries during the study period of one year was 2574. There were 1346 (52.29\%) vaginal deliveries and 1228 (47.7\%) Cesarean deliveries. The Cesarean section rate is high in our hospital as it is a tertiary care referral centre. Among 1228 cesarean deliveries, $87(7.08 \%)$ had maternal request as their indication. Estimates of caesarean delivery on maternal request range from 4-18 percent but there is little confidence in the validity of these estimates as CDMR is not a well-recognised clinical entity and there are currently no accurate means of reporting it. ${ }^{12,13}$ Of significance in the decision-analysis for women opting abdominal delivery should be the intended future family size. With rising caesarean section rates, placenta accreta becomes increasingly common. Silver et al found that placenta accreta was present in $0.24 \%, 0.31 \%, 0.57 \%$, $2.1 \%, 2.3 \%$ and $6.7 \%$ of women undergoing their first, second, third, fourth, fifth, and sixth or more caesarean deliveries, respectively. ${ }^{14}$ This was a consequence of both an increasing incidence of placenta praevia with repeated caesarean sections and an increased likelihood of placenta accreta where the placenta was located over the uterine scar. Placenta accreta and percreta may be associated with significant maternal mortality and morbidity including massive haemorrhage requiring emergency hysterectomy. Caesarean delivery may be associated in subsequent pregnancies with delayed conception, increased risk of ectopic pregnancy, possibly intrauterine growth restriction (IUGR), pre-term birth, unexplained stillbirth after 34 weeks and uterine scar dehiscence or rupture. ${ }^{15}$

A document by the American College of Gynecologists and Obstetricians in 2013 published guidelines for the cesarean section by request, which should only be performed after 39 weeks of gestation, never being done due to the absence of effective pain control mechanisms, and should be avoided in women who manifest a desire for numerous offspring. The review showed that, when compared with vaginal delivery, cesarean section by request showed a greater maternal length of hospital stay, a greater chance of neonatal respiratory problems (an issue only seen up to 39 weeks, with substantial improvement at 40 weeks or more), and a higher risk of complications such as hysterectomies and placenta accreta in subsequent pregnancies. On the other hand, elective cesarean section showed a lower rate of transfusions, bleeding, fewer surgical complications (vaginal delivery may require the use of forceps or emergency caesarean section), and lower chance of urinary incontinence in the first year postpartum and fetal brachial plexus injuries. Finally, and given the current level of knowledge, one cannot certify the superiority of a delivery route over another as regards to pain after delivery, pelvic pain, postpartum depression, fistulas and maternal mortality. ${ }^{16}$

\section{CONCLUSION}

The incidence of cesarean sections done on request without any medical indications is rising. The possibilities for this increase are not only for supposed medical benefit, but also may be due to social, cultural, and psychological factors. Despite there being improvements in the safety of anesthesia and surgery the morbidity and mortality are more for elective cesarean sections as compared to vaginal deliveries. Though an association exists between damage to the pelvic floor and childbirth, it cannot be attributed entirely to vaginal deliveries and may even occur even after a cesarean birth. Late intrauterine fetal demises may not be reduced by a policy of universal elective cesarean section. Caesarean section itself carries a risk of iatrogenic prematurity, morbidity and mortality. While dealing with a maternal request for cesarean section, obstetricians need to establish the reasons for the request and must provide clear, unbiased information based on the best available 
evidence. Management of labor should be individualized so as to facilitate women to have vaginal deliveries.

Funding: No funding sources

Conflict of interest: None declared

Ethical approval: The study was approved by the Institutional Ethics Committee

\section{REFERENCES}

1. Sahlin M, Carlander-Klint AK, Hildingsson I, Wiklund I. First-time mothers' wish for a planned caesarean section: deeply rooted emotions. Midwifery. 2013;29(5):447-52.

2. Wlklund I, Andolf E, Lilja H, Hildingson I. Indications for caesarean section on maternal request - Guidelines for counselling and treatment. Sexual Reprod Health Care. 2012;3:99-106.

3. National Institutes of Health State-of-the-Science Conference Statement. Cesarean Delivery on Maternal Request. Obstet Gynecol. 2006;107:138697.

4. RCOG Clinical Effectiveness Support Unit. The National Sentinel Caesarean Section Audit Report. London: RCOG Press;2001.

5. Al-Mufti R, McCarthy A, Fisk NM. Survey of obstetricians' personal preference and discretionary practice. Eur J Obstet Gynecol Reprod Biol. 1997;73:1-4

6. Helal AS, Abdel-Hady ES, Refaie E, Warda O, Goda $\mathrm{H}$, Sherief LS. Rising rates of caesarean delivery at Mansoura University hospital: a reason for concern. Gynecol Obstet. 2013;3:146.

7. WHO. Monitoring obstetric care: a handbook. Geneva: WHO Press, World Health Organization, 2009.

8. Chu K, Cortier H, Maldonado F, Mashant T, Ford N, Trelles M. Cesarean section rates and indications in
sub-Saharan Africa: a multi-country study from Medecins sans Frontieres. PLoS One. 2012;7:e44484.

9. Ye J, Betrán AP, Guerrero Vela M, Souza JP, Zhang J. Searching for the optimal rate of medically necessary cesarean delivery. Birth. 2014;41:237-44.

10. Nerum H, Halvorsen L, Sorlie T, Oian P. Maternal request for caesarean section due to fear of birth: can it be changed through crisis oriented counselling? Birth. 2006;33:221-8.

11. Paterson-Brown S, Fisk NM. Caesarean section: every woman's right to choose? Curr Opin Obstet Gynecol. 1997;9(6):351-5.

12. National Institutes of Health. NIH State of the science Conference statement on Cesarean delivery on maternal request. Bethesda. 2006:1-29.

13. Agency for Healthcare Research and Quality. Cesarean Delivery on Maternal Request. 2006.

14. Silver RM, Landon MB, Rouse DJ, Leveno KJ, Spong CY, Thom EA et al. Maternal morbidity associated with multiple repeat cesarean deliveries. Obstet Gynecol. 2006;107(6):1226-32.

15. D'Souza R, Arulkumaran S. To 'C' or not to 'C'? Caesarean delivery upon maternal request: a review of facts, figures and guidelines. J Perinat Med. 2013;41(1):5-15.

16. American College of Obstetricians and Gynecologists. ACOG committee opinion no. 559: Cesarean delivery on maternal request. Obstet Gynecol. 2013;121(4):904-7.

Cite this article as: Sri AS, Khanam N. An institutional study of cesarean delivery on maternal request. Int J Reprod Contracept Obstet Gynecol 2017;6:2879-82. 